ISSN 1983-8484

Licenciado sob uma Licença Creative Commons

\title{
Vulnerabilidade na cadeia de suprimentos de processamento e exportação da madeira tropical brasileira
}

\author{
Vulnerability in the supply chain operations in processing exports \\ of Brazilian tropical timber
}

Hanna Tatarchenko Welgacz ${ }^{[a]}$, Ubiratã Tortato ${ }^{[b]} J_{a n s e n}$ Maia del Corso ${ }^{[c]}$

[a] Doutoranda em Administração pelo Programa de Pós-Graduação em Administração da Pontifícia Universidade Católica do Paraná, Curitiba, PR - Brasil, e-mail: hannatw@terra.com.br

[b] Doutor em Administração, professor titular do Programa de Pós-Graduação em Administração da Pontifícia Universidade Católica do Paraná, Curitiba, PR - Brasil, e-mail: ubirata.tortato@pucpr.br

[c] Doutor em Administração, professor titular do Programa de Pós-Graduação em Administração da Pontifícia Universidade Católica do Paraná, Curitiba, PR - Brasil, e-mail: del.corso@pucpr.br

\section{Resumo}

O presente artigo busca de maneira sucinta descrever as principais atividades da cadeia de suprimentos de madeira tropical nativa brasileira. Esta pesquisa é caracterizada como descritiva quanto aos objetivos, ex post facto quanto ao controle de variáveis e estudo de caso quanto ao método de estudo. 0 método de estudo de caso permitiu apresentar os pormenores do processo estudado. Verificaram-se os vários procedimentos que envolvem diversas empresas participantes e as dependências entre si, bem como os pontos de vulnerabilidade para a cadeia de suprimentos. Exposta à vulnerabilidade, a cadeia de suprimentos não atinge as metas propostas e geram-se conflitos no canal. Isso traz resultados negativos para a competitividade das empresas envolvidas e insatisfação dos clientes no exterior.

Palavras-chave: Cadeia de suprimentos. Vulnerabilidade. Exportações.

\section{Abstract}

This article briefly describes tropical wood supply chain's activities in Brazil and timber export to the customers abroad. This research is characterized as descriptive, ex post facto and a case study. The case study method allows to present the details of the process studied. Dependence between the companies exposes supply chain to vulnerability as well as it is evidenced that high level of competitiveness in wood extractive industry would lead to low commitment and to opportunistic behavior. This paper contributes suggesting an interdisciplinary discussion between SCM and business strategy in order to found out vulnerability sources.

Keywords: Supply chain. Vulnerability. Exports. 


\section{Introdução}

Muitos autores reconhecem que o principal desafio da gestão da cadeia de suprimentos é a integração de todos os membros em um fluxo constante e sem interrupções imprevistos. No entanto, como qualquer procedimento que envolve múltiplos agentes, a cadeia de suprimentos também presencia instabilidade nos seus processos. Nesse sentido, Svensson (2002, p. 109) constata que na relação de dependência entre os participantes da cadeia de suprimentos, atividades e recursos podem causar consequências de natureza negativa quando ocorre variabilidade em qualquer sentido na cadeia de suprimento. Segundo o autor, medir e avaliar os pontos de vulnerabilidade levaria ao aumento da eficiência no fluxo logístico.

Em torno de $60 \%$ das exportações brasileiras se devem a agronegócios, como soja, açúcar, milho, suco de laranja, entre outros. Produtos de madeira também fazem parte da crescente e importante área de agronegócios. A indústria de base florestal é responsável por cerca de um milhão de empregos diretos e uma receita anual de US\$ 25 bilhões, contribuindo com $4 \%$ do PIB brasileiro e representando US \$4,2 bilhões em exportações (REVISTA MADEIRA, 2006). Existem cerca de 15.000 empresas do ramo madeireiro em atividade no País (IBAMA, 2006). Os Estados de maior peso no setor florestal de base nativa são Mato Grosso, Rondônia e Pará.

O objetivo deste artigo é constatar as fontes de vulnerabilidade da cadeia de suprimentos nas operações de processamento e exportação de madeira tropical brasileira. 0 propósito é fazer um paralelo entre o aporte teórico e a prática empresarial.

O setor de agronegócios é estratégico para economia brasileira. Poucos estudos em particular sobre produtos de base florestal podem ser observados na literatura. 0 presente trabalho pretende contribuir com a descrição dos pormenores da cadeia de suprimentos da madeira tropical nativa brasileira e exposição dos seus pontos críticos. Ainda apresenta-se exemplo de uma operação de exportação de produto de agronegócios, que não flui como deveria, mas com constantes constrangimentos por parte dos terceiros.

0 artigo é composto por cinco seções, incluindo a introdução. A segunda seção é composta por referencial teórico, onde são apresentados princípios da gestão da cadeia de suprimento e conceitos da vulnerabilidade. A seção três trata da metodologia deste trabalho. Na seção quatro será descrito o caso das empresas estudadas e serão discutidos os pontos onde se encontra vulnerabilidade da cadeia. A finalidade da quinta seção, a conclusão, é trazer os principais pontos do aporte teórico e a prática empresarial do caso estudado.

\section{Referencial teórico}

Esta sessão trata inicialmente dos conceitos que compõem o entendimento da cadeia de suprimentos e suas funções. Na sequência são abordadas situações que constatam existência de instabilidade na cadeia de suprimentos: vulnerabilidade, conflitos e formas de solução.

\section{Conceito da cadeia de suprimentos}

Os recentes estudos da gestão da cadeia de suprimentos retratam a evolução das abordagens desse campo. Embora existam diversas definições para esta área, atualmente a grande parte dos estudiosos concorda que a cadeia de suprimentos é uma disciplina com amplo escopo de estudo. Frankel et al. (2008) definem cadeia de suprimentos com foco de integrar funções de compra, gestão de operações, logística e canais de distribuição dentro e entre empresas. Os autores encontram entre diferentes definições para gestão da cadeia de suprimentos uma característica comum, que é a integração de múltiplas disciplinas, enquanto a unidade de análise evolui para estudos de redes entre múltiplos clientes e fornecedores.

Para compreensão das questões e temas a serem retratados neste estudo, para a definição da gestão de cadeia de suprimentos adota-se o conceito do Council of Supply Chain Management Professionals (CSCMP):

Gestão da cadeia de suprimentos é planejamento e gerenciamento de todas as atividades envolvendo fornecimento e compras, conversão e todas as atividades logísticas. Importante, que inclui também coordenação e colaboração com parceiros do canal, que podem ser fornecedores, intermediários, fornecedores de serviço terceirizados e clientes. Em essência, gestão da cadeia de suprimentos integra fornecimento e demanda dentro e entre empresas (FRANKEL et al., 2008, p. 1). 
Nesse sentido, exemplos das funções que a gestão da cadeia de suprimentos abrange são compras, programação da produção, processamento de pedidos, gerenciamento de estoque, transporte, armazenagem e serviço ao cliente. Observa-se que as modernas cadeias de suprimentos são muito complexas, ocorrendo muitos fluxos físicos e de informação paralelos (SUPPLY CHAIN..., 2002).

A busca de otimização da cadeia de suprimentos é constante. Os principais objetivos da gestão incluem atingir um nível eficiente de serviços/produtos com redução de custos, visando redução ou até eliminação das etapas que não agregam valor ao produto. Gomes e Ribeiro (2004) descrevem que a gestão da cadeia de suprimentos trata da coordenação e integração de fluxos de produtos, informações e finanças entre várias empresas. Os autores destacam que o foco da cadeia de suprimentos não é mais a integração vertical, pois atualmente cada empresa está focada naquelas atividades que tem competência de realizar com sucesso. Disso decorre que uma das metas da gestão está na redução dos estoques.

Atualmente existe consciência de que uma cadeia de suprimentos integrada contribui para o desenvolvimento das estratégias organizacionais competitivas. Para garantir eficiência das operações, as empresas assumem parcerias na prestação de serviços e fornecimento de produtos. Está evidente que em trabalho conjunto surge dependência entre os envolvidos. Com o fator de dependência surge a vulnerabilidade da cadeia toda, já que existe incerteza quanto ao desempenho de cada empresa envolvida. A seguir é tratado o conceito de vulnerabilidade na cadeia de suprimentos.

\section{Vulnerabilidade na cadeia de suprimentos}

A cadeia de suprimentos forma uma rede ou canal de diversas empresas que buscam atingir suas metas próprias ou, às vezes, mútuas. A complementaridade das atividades sugere a dependência entre empresas envolvidas. A dependência, segundo Svensson (2002), pode ser de três tipos: de tempo, de relação e funcional. Por dependência de relação entendem-se adaptações técnicas, coordenação, conhecimentos sobre parceiros, laços sociais, econômicos e jurídicos. Já aspectos de dependência de tempo dizem respeito a curto ou longo prazo das relações citadas acima e assumidas por empresas. Existe também dependência funcional entre empresas, que se refere à complementaridade das atividades desempenhadas por cada uma dentro da cadeia de suprimentos. A dependência leva à necessidade de cooperação e coordenação entre empresas para atingirem as suas metas. Ao mesmo tempo, a dependência entre empresas causa vulnerabilidade da cadeia de suprimentos.

Destaca-se que são poucos estudos que tratam da vulnerabilidade das atividades entre empresas e os gerentes são pouco alertados sobre este assunto. A mudança das abordagens em direção à cadeia mais enxuta resultou em configuração de redes mais vulneráveis. Por exemplo, em caso de interrupção, a tendência de manter pequeno inventário e baixo nível do sistema "buffer" leva ao imediato impacto na cadeia toda. As interrupções podem ser de diversas naturezas: desastres naturais, acidentes, ações diretas do setor econômico, ações terroristas e dificuldades operacionais. Considerando os crescentes riscos, as empresas estão atentas para elaborar planos de emergência para casos de interrupção de produção e quando será necessária para perda de uma parcela de mercado, aumento de custos, outros (SUPPLY CHAIN..., 2002).

A proposta de Asbjørnslett e Rausand (1997) de taxonomia dos fatores de vulnerabilidade em primeiro lugar faz a distinção entre sistema robusto e vulnerável. Na opinião dos autores, um sistema robusto é capaz de absorver as perturbações sem falhar e continuar intacto, enquanto um sistema vulnerável está na outra ponta oposta desse continuum de resistência sistêmica. Autores distinguem dois tipos de fatores de vulnerabilidade, externos e internos. Enquanto fatores internos ou "in-house" podem ser controlados, os externos ou "out-house" ou "outsourced" são controlados indiretamente, caso ainda sejam passíveis de controle. Destacam ainda os autores que análise de vulnerabilidade não é o mesmo que análise de riscos. A última tem foco nas consequências dos eventos acidentais, enquanto análise de vulnerabilidade se preocupa com sobrevivência e estabilidade do sistema.

0 construto de vulnerabilidade elaborado por Svensson (2002) consiste em dois componentes: i) perturbação; e ii) consequência negativa da perturbação. Perturbação é definida como desvio qualitativo ou quantitativo do resultado normal ou esperado. Já as consequências negativas da perturbação referem-se à incapacidade de atingir as metas estabelecidas (em termos econômicos, quantitativos, aumentam 
ciclos de produção, bem como deterioração da qualidade dos processos). Em suma, Svensson (2002, p. 112) define que a "vulnerabilidade é a condição que afeta o alcance das metas da empresa" caso ocorram consequências negativas da perturbação. 0 grau de vulnerabilidade pode ser definido como a probabilidade de ocorrência de uma perturbação com consequências negativas. No entendimento do autor, as empresas conseguem diminuir a vulnerabilidade dos seus fluxos logísticos quando introduzem atividades preventivas. Na proposta do autor, medir e avaliar os pontos de vulnerabilidade levaria ao aumento da eficiência no fluxo logístico.

Svensson (2002) define que vulnerabilidade na cadeia pode acontecer nos fluxos de dentro da organização (inbound) e nos de fora (outbound). Como primeiro passo da sua metodologia, é verificado se existe a dependência entre empresas do mercado. Em um segundo momento o autor procura conceituar os tipos de dependência. Exemplifica-se que no processo just-in-time o conceito de dependência entre atividade das empresas pertencentes à cadeia de suprimentos é reforçado causando a vulnerabilidade. Desta maneira, a adoção do sistema just-in-time seria indicada em cadeias totalmente integradas. 0 autor define quatro dimensões da vulnerabilidade: nível de serviço, desvio (divergência), consequência e tendência. Seu estudo empírico realizado na empresa automobilística Volvo analisa os fluxos inbound e outbound da organização e encontra dependência da empresa em relação aos seu fornecedores e clientes.

A necessidade de conhecer a vulnerabilidade na cadeia de suprimentos tem justificativa. A partir do diagnóstico das fraquezas internas e ameaças externas pode ser traçado o quadro do risco que envolve a cadeia toda. $O$ conhecimento da vulnerabilidade da cadeia é vital para formulação e implementação da estratégia da cadeia de suprimentos.

0 risco que surge na cadeia de suprimentos deriva da interação entre empresas constituintes. A vulnerabilidade é causada pela interação e cooperação subotimizada ao longo da cadeia. 0 risco eminente é resultado da falta de visibilidade, falta de práticas just-in-time, previsões imprecisas, entre outros (SUPPLY CHAIN..., 2002).

0 estudo da vulnerabilidade na cadeia de suprimentos desenvolvido por Peck (2005) foi realizado na indústria aeroespacial no Reino Unido. A autora propõe quatro níveis de análise: i) fluxo de valor, processo ou produto; ii) dependência da infraestrutura e ativos; iii) sistemas organizacionais e interorganizacionais; e iv) o ambiente natural e social. 0 estudo empírico comprovou que nessas dimensões podem ser encontrados fatores que representam risco para estabilidade da cadeia de suprimentos. As conclusões do estudo levam a avaliar a interdependência dessas dimensões e a necessidade de se ter gestores da área eficientes e preparados, o que nem sempre acontece na prática.

Observa-se que a vulnerabilidade da cadeia de suprimentos está nas pessoas e na infraestrutura. Pontos críticos indicados por autores já citados levam a acreditar que o fluxo mais confiável de informações entre os envolvidos é um caminho para aumentar eficiência do processo.

Outros conceitos fazem parte do escopo do entendimento da vulnerabilidade na cadeia de suprimentos. 0 poder pode ser entendido como oposto da dependência. Ou seja, quanto mais poder um elo da cadeia detém, menos dependência esta empresa terá em relação aos outros participantes. No entanto, o poder não deve ser entendido como sinônimo da vulnerabilidade. Da mesma maneira, outro aspecto, o conflito, pode surgir, mas não necessariamente em decorrência do poder ou dependência. 0 conflito será relacionado com o construto de vulnerabilidade caso gere consequências negativas, como as pressupõe o conceito da vulnerabilidade (SVENSSON, 2002).

Outros componentes que podem surgir para elucidar pontos críticos na vulnerabilidade da cadeia são riscos, incerteza, comprometimento dos parceiros. Svensson (2002) destaca que estes aspectos não têm o mesmo conceito da vulnerabilidade, mas geram a vulnerabilidade em caso de ocorrência das consequências negativas para a cadeia de suprimentos.

Craighead et al. (2007) elaboraram seis propostas referentes à incidência de perturbações dependendo do desenho e capacidades da cadeia de suprimentos. Os autores argumentam que perturbações associadas a custos operacionais e financeiros podem ser vistos como corriqueiros. No entanto, outros fatores são essencialmente críticos. Entre suas proposições destaca-se a colocação de que em cadeias mais "densas" as interrupções imprevistas geram consequências mais graves do que em menos "densas" e menos complexas. Uma importante contribuição desse estudo empírico foi também constatar que uma cadeia que tenha capacidade de rapidamente detectar e disseminar informações sobre o evento indesejado tem maior sucesso na resposta. 
Concluindo esse breve referencial teórico observa-se que com as atuais transformações econômicas nacionais e globais, se questiona cada vez mais o papel da cadeia de suprimentos. Não é surpreendente o crescimento da sua importância dentro do contexto de desenvolvimento da estratégia das empresas. Com isto, as propostas de pesquisa neste campo ficam amplas, sugerindo estudos sobre gargalos na cadeia de suprimentos.

\section{Metodologia}

Em aspectos metodológicos esta pesquisa é caracterizada como descritiva quanto aos objetivos, ex post facto quanto ao controle de variáveis e estudo de caso quanto ao método de estudo. 0 estudo de caso foi escolhido por possibilitar a abrangência de ocorrência dos fenômenos e contextos onde estão inseridos (YIN, 2005).

A amostra do estudo é representada por duas empresas exportadoras de produtos florestais, duas serrarias, dois despachantes aduaneiros, uma transportadora rodoviária e dois importadores europeus. As referidas empresas brasileiras são situadas nas cidades de Curitiba e Paranaguá, estado do Paraná; e cidade de Ariquemes, Estado de Rondônia. Um importador europeu entrevistado se encontra na Bélgica e outro na França. As entrevistas foram conduzidas pessoalmente e quando não foi possível a presença física do entrevistado, via telefone. 0 critério utilizado para escolha da amostra, em função da facilidade de acesso aos dados, foi de caráter intencional. A técnica de coleta de dados primários foi entrevista semiestruturada com gerentes de produção, executivos da área de comércio exterior e logística dessas empresas.

0 nome das empresas estudadas foi preservado devido à solicitação de suas diretorias, por esta razão no decorrer do trabalho as mesmas serão denominadas de acordo com suas funções exercidas.

\section{Apresentação e análise de dados}

A seguir é descrita a cadeia de suprimentos da madeira tropical nativa brasileira desde o corte da árvore até a entrega do produto final ao importador. Na Figura 1 são mostradas organizações que são envolvidas na operação e suas respectivas funções.
Observa-se que da operação participam tanto empresas privadas como instituições públicas, estas últimas são necessárias para fornecer anuência para trânsito e exportação da madeira. Nesta etapa surge o questionamento de definir quem pertence à cadeia de suprimentos no caso estudado. Recorrendo à definição da cadeia de suprimentos, temos como participantes aquelas empresas que são fornecedores, intermediários, fornecedores de serviço terceirizados e clientes e que efetuam planejamento e coordenação das atividades envolvendo fornecimento e compras, logística, entre outros (FRANKEL et al., 2008). Portanto, para efeitos do estudo pode-se concluir que instituições públicas não pertencem à cadeia de suprimentos, mas somente empresas privadas, responsáveis por etapas de corte das árvores em área de manejo, serrarias, exportadores, transportadores, armazéns, terminal de contêiner, armadores e importadores.

\section{Etapa de produção}

As duas exportadoras de produtos florestais estudadas são empresas com sede em Curitiba-PR, cujo core-business é exportação de toda a sua produção. Seu produto principal é a madeira tropical brasileira, serrada e seca em estufa, exportada para mercados dos Estados Unidos, Canadá, Bélgica, França, China, Taiwan, Vietnam, Indonésia, entre outros.

Para o presente estudo será explorada a cadeia de suprimentos da madeira da espécie Tauari (Couatari oblongifolia), também chamada na região de Rondônia e Mato Grosso pelo nome comum de Embireira, Imbirema, Tauari-amarelo ou Tauarimorrão. Essa árvore nativa da floresta amazônica atinge de 25 a 30 metros de altura e um a dois metros de diâmetro. Seu cerne é claro e com leve aroma. Essas características contribuem para que, imediatamente após o corte, sua cor tenda para o azulamento, ou seja, escurecimento rápido da superfície cortada e também para a sua contaminação por larvas que produzem perfurações na madeira de até meio centímetro de diâmetro, diminuindo o seu valor comercial ou até inviabilizando a sua venda. Para combater esses aspectos negativos, as pontas da tora, logo após o seu corte, são tratadas com agroquímicos a base de cupinicida. As toras devem ser usadas na produção em poucos dias, pois o risco de deterioração da matéria-prima é muito alto mesmo após o tratamento 


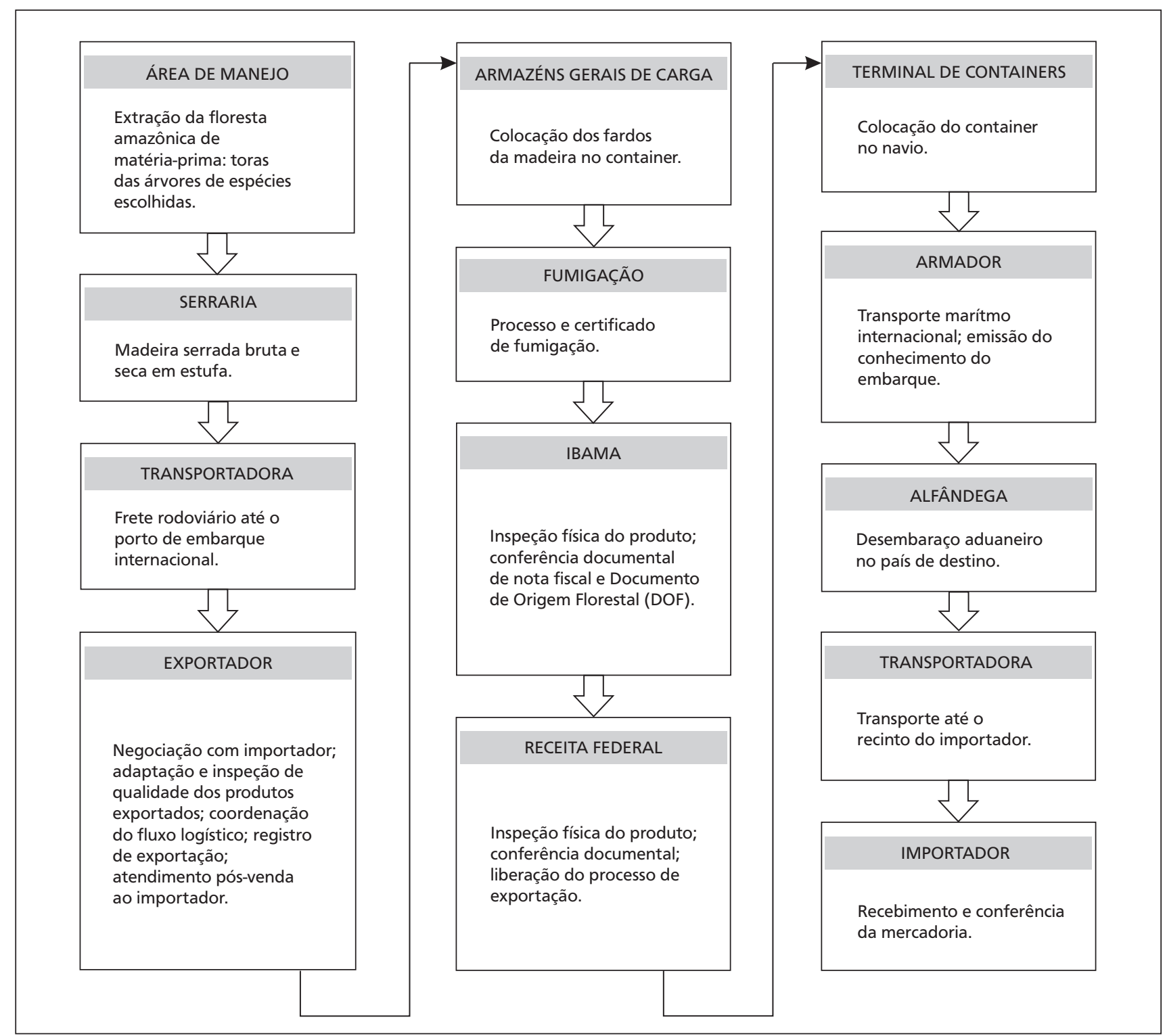

Figura 1 - Visualização dos envolvidos no processamento e exportação da madeira Fonte: Dados da pesquisa.

com veneno. A alta umidade do ar durante a estação chuvosa na região amazônica, que se estende de novembro a maio, contribui para rápida proliferação de larvas. Por esta razão não acontece extração dessa e de outras espécies de cerne branco neste período.

A obtenção da matéria-prima representa o principal fator de incerteza para a produção. A irregularidade de fornecimento e, além disso, a probabilidade de que esta não esteja em conformidade com o padrão necessário é muito alta. As árvores podem apresentar defeitos naturais, como trincas, cupins, nós. As toras são extraídas da floresta amazônica e estas podem apresentar muitos problemas, desde a sua recepção pela serraria até o seu processamento para a produção de tábuas.

As toras são adquiridas de empresas especializadas em extração de madeira da floresta amazônica que o fazem ou da própria área de manejo ou de outras áreas mediante contrato. A origem da madeira da área de manejo é comprovada por documento oficial (DOF - Documento de Origem Florestal) exigido pelo Ibama para controle de tráfego de produtos florestais no Brasil. Sem este documento nenhum produto florestal pode fazer trânsito no território nacional e o mesmo é exigido para a saída da madeira da fronteira do Brasil para a exportação. 
As empresas exportadoras estudadas optaram por não possuir a área própria de manejo florestal, pois distinguem como seu negócio principal a exportação de madeira tropical. Aquisição de terrenos e áreas de manejo para corte de determinadas espécies iria imobilizar seus ativos. Tal decisão ainda é reforçada pela visualização de riscos atribuídos à administração de áreas de manejo. A frequente intervenção governamental no campo da regulamentação florestal é vista pela diretoria dessas empresas como um investimento de alto risco. Tampouco as empresas estudadas possuem ativos em serrarias ou estufas. Visto que o seu potencial de colocar produto no exterior demanda uma quantidade que é atendida por quarenta serrarias contratadas nos estados de Mato Grosso e Rondônia, imobilização em ativos seria excessivamente dispendiosa.

As serrarias que atendem as exportadoras são responsáveis pelas etapas de corte e secagem da madeira. 0 corte da tora acontece no sentido longitudinal, resultando em tábuas de espessura constante devido à regulagem da serra. Todas as tábuas devem apresentar a uniformidade na espessura em toda a sua extensão, sendo que o descumprimento de tal condição pode levar a recusa do lote pelo cliente. Devido à baixa precisão do equipamento de corte das serrarias, é frequente a falta de uniformidade das tábuas, o que representa um fator de vulnerabilidade do negócio. Para reduzir este risco, a tábua é cortada 3 a $4 \mathrm{~mm}$ mais espessa do que o solicitado para garantir que não haja locais com espessura abaixo da solicitada (undersize). Além disso, o corte com abono considera que a madeira após secagem em estufa encolhe em todas as dimensões: espessura, largura e comprimento. 0 planejamento do corte também considera estes pormenores.

Após o corte longitudinal da tora, as tábuas resultantes desse processo recebem tratamento de cupinicida em toda a sua superfície através de um breve mergulho em reservatórios com este líquido. A etapa de tratamento com cupinicida pode necessitar ser repetida em várias etapas de preparação de madeira. 0 breve escurecimento da madeira faz com que sua entrada na estufa deva acontecer logo após o corte, e lá permanece de oito a dezesseis dias, dependendo da espessura das tábuas. Quanto maior a espessura maior será a sua permanência na estufa para diminuir o grau de umidade. 0 processo de secagem deve ser conduzido com conhecimento das propriedades da espécie utilizada. Caso contrário, a madeira seca será de péssima qualidade, terá trincas e fibra de madeira estourada, além de entortamento das tábuas.

Como pode ser observado da descrição acima, o processamento da madeira possui certo grau de complexidade e incertezas quanto à qualidade da matéria-prima e produto pronto. Neste sentido, as serrarias pressionam seus fornecedores para receber toras de boa qualidade. Por sua vez, exportadores cobram serrarias por fornecimento de tábuas de excelente qualidade, conforme especificado por seus clientes no exterior.

Nesta etapa de produção os conflitos que podem ocorrer entre as empresas envolvidas são:

a) fornecedor de toras pode atrasar a entrega da matéria-prima para serraria, por questões de difícil acesso a árvores na floresta, mão de obra não preparada, período de chuvas intensas, e por falta de projetos de corte legal aprovados;

b) serrarias instaladas na floresta amazônica, no caso estudado no estado de Rondônia, podem atrasar a entrega dos pedidos às exportadoras. Aconteciam também casos quando a serraria não honrava o pedido que recebia da exportadora. Caso aparecesse outro comprador na porta da serraria, que pagasse pouco mais e à vista, a serraria entregava o pedido produzido para este outro comprador. Esta falta de fidelidade é gerada, entre outras razões, por pouco comprometimento da serraria com seus clientes e, ainda, por problemas com fluxo de caixa. Para garantir a produção os exportadores muitas vezes fazem adiantamento do pagamento às serrarias do pedido a ser produzido;

c) exportador, para evitar situações de deslealdade, mantém um funcionário na região das serrarias contratadas. Tal funcionário supervisiona a qualidade do produto, andamento da produção e prazos de entrega.

\section{Transporte interno}

Nas etapas posteriores ao processamento da madeira acontece prestação de serviços por parte de outras empresas envolvidas. Os exportadores compram das serrarias a madeira já serrada e seca em estufa, classificada e embalada em pallets. 0 exportador contrata o transporte rodoviário da madeira da região amazônica 
até o porto de embarque. 0 transporte rodoviário é terceirizado e o exportador contrata uma empresa transportadora ou um autônomo. A distância da cidade de Ariquemes até o porto de Paranaguá é de $3.000 \mathrm{~km}$. 0 valor do frete é alto, muitas vezes supera o valor do frete marítimo internacional até um porto europeu.

Alto valor do frete, no entanto, não reflete boa qualidade de serviço. É frequente o transportador não cumprir o prazo de entrega, pois a viagem toma em torno de 4 dias do estado de Rondônia até o porto de Paranaguá, no Paraná. Este prazo pode se estender em alguns casos para 7 a 10 dias. Em períodos de safra da soja, o frete aumenta de valor, o que muitas vezes inviabiliza o transporte interno da madeira. Nestes períodos o valor do frete é mais alto e, ainda, frequentemente indisponível.

\section{Recebimento da madeira para exportação}

Para evitar surpresas desagradáveis com a qualidade da madeira, o exportador tem estrutura física de armazenamento e funcionários para receber e inspecionar madeira no porto. Mesmo com esforços de manter o padrão de qualidade desde a origem da madeira, não é raro o exportador receber da serraria uma madeira de má qualidade, com grau de umidade diferente do especificado, medidas diferentes, ou até defeitos como nós, cupins, que não são aceitos pelos importadores no exterior.

\section{Atraso na escala do navio por parte do armador}

A atracação dos navios no porto segue uma escala, geralmente semanal. A chegada dos navios, embora possua programação para meses na frente, sofre frequentes atrasos. Esses atrasos podem chegar a 3, 4 dias. Os armadores, que são proprietários dos navios, e agências que representam armadores nos portos, remanejam as cargas de acordo com as suas prioridades. Enquanto isto, a carga permanece retida no porto, esperando a chegada do navio. Armadores também praticam cancelamento de entrada dos navios no porto e fazem escolha arbitrária sobre a carga que vai embarcar no navio escalado. Frequentemente deixam carga "no chão", postergando o embarque para o próximo navio, sem consentimento do exportador para isto. Enquanto os navios são semanais, o atraso mínimo no processo de embarque é de sete dias. Importante destacar que a reserva do espaço no navio acontece via correio eletrônico ou via telefone, no entanto, estes acordos não garantem o comprometimento das partes. Atrasos nos embarques geram novos custos para exportadores e, consequentemente, para importadores também.

Os atrasos nos embarques também geram custos de armazenagem não previstos. Surge também o custo de demurrage, que é o custo de retenção de contêiner cobrado pelo armador, proprietário do contêiner e que o cedeu alguns dias antes de embarque. 0 armador fornece o contêiner para o exportador por 5 a 7 dias livres de pagamento do uso. Caso o exportador não embarque o contêiner neste período, o armador começa a cobrar pela retenção de contêiner, e o custo chega a US $\$ 60,00$ por dia.

Demoras no embarque geram, além de custos visíveis e contábeis, como armazenagem e retenção de contêiner, também custos de perda da oportunidade de investimento para o exportador, acarretados pelos atrasos no faturamento das mercadorias a serem exportadas. Procedimentos no comércio internacional regem que o importador paga pelas mercadorias somente depois do recebimento da documentação do embarque. A documentação inclui a emissão, por parte do armador, de Conhecimento de Embarque Marítimo (Bill of Lading), que comprova o embarque da mercadoria no navio. Outra documentação, como fatura comercial, packing list e certificados, também são exigidos por grande parte dos importadores para efetuar o pagamento do exportador.

0 ponto vulnerável no fluxo do processo de exportação neste caso está na relação entre exportador e armador, gerado pelas falhas do último. Por outro lado, deve ser mencionado que o exportador também pode atrasar o embarque do contêiner no espaço reservado por conta do aumento do prazo de produção da serraria, transporte interno demorado, reclassificação do produto, devolução do lote à serraria, entre outras razões. Neste caso, o armador recebe notificação do exportador 3-4 dias antes do prazo de embarque, de que o espaço reservado no navio para determinada data não será utilizado. Como as reservas dos navios sempre estão com overbooking, a recusa do embarque por parte do exportador não gera consequências negativas para o armador, que facilmente remaneja outras cargas no lugar liberado.

No item a seguir serão discutidas as implicações do constatado no caso descrito para a teoria de gestão da cadeia de suprimentos e para a prática empresarial, 
bem como serão expostas sugestões de planos de contingência para situações de vulnerabilidade na cadeia.

\section{Discussão}

No caso descrito acima se constatou a presença de vulnerabilidade na cadeia de suprimentos da madeira tropical para exportação. Os pontos de vulnerabilidade encontram-se especialmente nos fluxos de fora da organização (outbound) (SVENSSON, 2002). Isto é decorrente da dependência entre as firmas envolvidas na cadeia. Em relação à cadeia de suprimentos analisada, constatou-se que:

a) 0 sistema é vulnerável, já que não apresenta estabilidade e capacidade de recuperação imediata após eventos de perturbação, como descrevem Asbjørnslett e Rausand (1997). Um sistema robusto seria capaz de absorver perturbações sem consequências negativas, enquanto o sistema analisado é vulnerável, pois não apresenta resistência sistêmica;

b) Os tipos de dependência encontrados são do tipo funcional (SVENSSON, 2002). Nas etapas de extração de toras da área de manejo, produção da serraria, exportador e transporte interno, está o exemplo da dependência do tipo funcional, já que todas as atividades são complementares para atingir a meta de exportação. Em pontos frágeis da cadeia de suprimentos são suscetíveis de acontecerem oscilações no nível de qualidade do produto/serviço ofertados. Não preenchendo as expectativas do importador, o fornecedor gera insatisfação, o que consequentemente leva a conflitos entre as partes.

Estas divergências entre metas colocadas e resultados reais na cadeia de suprimentos geram inconveniências para o importador. Os problemas são do tipo: atraso na entrega do produto no destino final, eventualmente problemas com qualidade de produto, que pode acontecer mesmo depois de detalhada inspeção por parte do exportador. Razões para isto são: escassez de matéria-prima de boa qualidade; aumento no lead time da produção da serraria; reclassificação por parte do exportador; aumento do tempo de trânsito do transporte interno; "rolagem" da carga por parte do armador e aumento de tempo de trânsito do frete marítimo internacional. Os importadores europeus entrevistados constataram estas inconveniências. $\mathrm{Na}$ opinião dos dirigentes dessas empresas, mesmo trocando de fornecedor e escolhendo algum outro exportador brasileiro, os problemas persistem, pois a cadeia de suprimentos no Brasil funciona nestes moldes e nesta velocidade.

Outro ponto que explica a vulnerabilidade da cadeia é o seu formato. Observa-se que são diversas empresas que interagem e a cadeia é relativamente densa (CRAIGHEAD et al., 2007). Isto é resultado da necessidade de empresas terceirizarem serviços e produção com objetivos de possuir uma produção enxuta. Por exemplo, para não ter estoques, o exportador opta por terceirizar a produção, bem como o transporte interno. Esta tendência de manter a cadeia mais enxuta resulta em configuração de redes mais vulneráveis. Por isto, em caso de atrasos na produção, a tendência de manter pequeno inventário leva ao imediato impacto na cadeia toda.

A solução de conflitos pode se dar de diversas maneiras. Na cadeia estudada esta solução não é resolvida facilmente, pois não existem contratos tácitos que fazem valer o combinado previamente entre os parceiros. Está evidente que neste tipo de negocio é impossível implantar algum método de suprimentos integrado, como, por exemplo, just in time (JIT). JIT é um sistema de excelência, que reforça a dependência funcional e de tempo entre atividades da empresa, o que consequentemente causa vulnerabilidade. Ao mesmo tempo, o comprometimento entre as partes leva a menos interrupções, perturbações no canal e aumento da qualidade. No caso estudado foi observado que não existe comprometimento por parte das empresas envolvidas, portanto, é impossível a implantação desse tipo de sistema.

Outra razão que leva a pensar sobre inviabilidade de implantação de um sistema integrado é a incerteza quanto à qualidade da matéria-prima e produto final. Nesta situação, o elo produtivo, que é o fornecedor de tora e serraria, está em situação de incerteza quanto à qualidade de tora que vai receber. Por isto a busca de diminuir seus custos reflete na baixa qualidade do produto entregue ao exportador.

\section{Conclusões}

O objetivo deste artigo foi apresentar e discutir a forma de organização da cadeia de suprimentos 
de processamento e exportação da madeira tropical brasileira. Para tanto se verificaram as relações entre os diversos atores que compõem a cadeia. Desta verificação constatou-se que:

a) a vulnerabilidade pode surgir na cadeia de suprimentos que apresenta dependência entre empresas participantes;

b) a vulnerabilidade é o construto que é composto por dois componentes: perturbação e consequência negativa dessa perturbação;

c) o grau de vulnerabilidade é proporcional à probabilidade de ocorrência de desvio dos resultados desejados ou esperados.

Dentro do contexto estudado de exportações brasileiras da madeira tropical nativa, a pesquisa levantou quatro pontos de vulnerabilidade onde podem ocorrer conflitos na cadeia de suprimentos:

a) etapa de produção: irregularidade na qualidade do produto entregue pela serraria ao exportador;

b) etapa de entrega: falta de comprometimento por parte da serraria com o exportador quanto ao cumprimento do pedido acordado para produzir;

c) transporte interno: falta de compromisso com o exportador;

d) transporte internacional: atraso na escala do navio por parte do Armador.

São diversas implicações ao se analisar vulnerabilidade na cadeia de suprimentos. É importante destacar que pontos de vulnerabilidade são aspectos críticos para aproveitar oportunidades de obter melhor desempenho. Os desdobramentos da análise levam a pensar que as empresas brasileiras giram menos seus estoques, sua lucratividade diminui e a competitividade consequentemente também. Atrasos gerados impactam também negativamente na imagem da empresa e do país, correndo riscos de os importadores optarem por outro exportador ou até fornecedor de outro país.

A detecção destas situações adversas é uma maneira de apontar possíveis pontos de melhoria na eficiência das operações. Cabe propor estudos complementares e de maior amplitude que venham a corroborar os resultados aqui demonstrados.

\section{Referências}

ASBJØRNSLETT, B. E.; RAUSAND, M. Assess the vulnerability of your production system. Report NTNU 97018. Norwegian University of Science and Technology NTNU, Department of Production and Quality Engineering, Trondheim Norway, 1997.

CRAIGHEAD, C. W. et al. The severity of supply chain disruptions: design characteristics and mitigation capabilities. Decision Sciences, v. 38, n. 1, p. 131-156, 2007.

FRANKEL, R. et al. The domain and scope of SCM's foundational disciplines - insights and issues to advance research. Journal of Business Logistics, v. 29, n. 1, p. 1-30, 2008.

GOMES, C. F. S.; RIBEIRO, P. C. C. Gestão da cadeia de suprimentos integrada à tecnologia de informação. São Paulo: Cengage Learning, 2004.

INSTITUTO BRASILEIRO DO MEIO AMBIENTE E DE RECURSOS NATURAIS RENOVÁVEIS - IBAMA. Brasil, 2006. Disponível em: <www.ibama.gov.br>. Acesso em: 10 set. 2010.

PECK, H. Drivers of supply chain vulnerability: an integrated framework. International Journal of Physical Distribution \& Logistics Management, v. 35, n. 4, p. 210-232, 2005.

REVISTA MADEIRA - REMADE. Brasil, 2006. Disponível em: <www.remade.com.br>. Acesso em: 10 set. 2010.

SVENSSON, G. A conceptual framework of vulnerability in firms' inbound and outbound logistics flows. International Journal of Physical Distribution \& Logistics Management, v. 32, n. 2, p. 110-134, 2002.

SUPPLY CHAIN VULNERABILITY. Executive report on behalf of: department for transport, local government and the regions. Department of Trade and Industry. Cranfield University, School of Management, UK, January 2002. Disponível em: <http://www.som.cranfield.ac.uk/som/dinamic-content/research/lscm/downloads/Vulnerability_ report.pdf >. Acesso em: 3 fev. 2011.

YIN, R. K. Estudo de caso: planejamento e métodos. 3. ed. Porto Alegre: Bookman, 2005.

Recebido: $26 / 05 / 2011$

Received: 05/26/2011

Aprovado: 29/08/2011

Approved: 08/29/2011 